\title{
Prevalence of hepatitis $C$ virus infection in patients hospitalised for ischemic heart disease versus controls - PRO-CARDIO-C study
}

\author{
Anna Piekarska' ${ }^{1}$ Aleksandra Mamzer-Dachnowska², Jarosław D. Kasprzak² Jan Z. Peruga², Andrzej Kaszuba³ \\ Aleksandra Berkan-Kawińska ${ }^{4}$ \\ ${ }^{1}$ Department of Infectious Diseases and Hepatology, Medical University of Lodz, Poland \\ ${ }^{2}$ Chair and Department of Cardiology, Medical University of Lodz, Poland \\ ${ }^{3}$ Department of Dermatology, Medical University of Lodz, Poland \\ ${ }^{4}$ Department of Infectious Diseases and Hepatology, Medical University of Lodz, Poland
}

\begin{abstract}
Aim of the study: Ongoing national screening programmes suggest that the prevalence of chronic hepatitis $C$ (CHC) in Poland ranges between $0.5 \%$ and $1 \%$. It has been recently noted that patients with confirmed coronary artery disease may be at higher risk for hepatitis C virus (HCV) infection.

Material and methods: Testing for the presence of anti-HCV antibodies was performed in a group of patients admitted to the Cardiology Department with symptomatic ischemic heart disease (IHD) and in patients hospitalised in the Dermatology Department.

Results: A total of 1171 patients underwent anti-HCV testing: 672 patients in the Cardiology Department (K group) and 499 patients in the Dermatology Department (D group). Twenty-eight (2.4\%) positive anti-HCV results were detected. The prevalence of positive anti-HCV antibodies in groups $\mathrm{K}$ and $\mathrm{D}$ was $2.23 \%$ and $2.61 \%$, respectively $(p>0.05)$. Presence of HCV RNA was confirmed in 15 cases $(1.28 \%)-7$ patients in group K and 8 patients in group D $(1.04 \%$ and $1.6 \%$, respectively; $p>0.05)$.

Conclusions: Our findings suggest that this patient cohort has increased risk of HCV infection, which may influence screening strategies.
\end{abstract}

Key words: hepatitis C, coronary artery disease, anti-HCV antibody, screening, HCV treatment.

Address for correspondence

Dr hab. Anna Piekarska, Department of Infectious Diseases and Hepatology, Medical University of Lodz, Poland, e-mail: annapiekar@op.pl

\section{Introduction}

Hepatitis C virus (HCV) infection remains a significant epidemiological health problem. Globally, an estimated 185 million people have been infected with HCV [1-3]. The World Health Organization (WHO) estimations in recent months show a decreasing number of patients to 71 million. Ongoing national screening programmes indicate that prevalence of chronic hepatitis $\mathrm{C}$ (CHC) in Poland ranges between $0.5 \%$ and $1 \%$ [4]. The number of patients with $\mathrm{CHC}$ undergoing antiviral therapy compared to the number of newly diagnosed HCV infections in blood donors suggests that the rate of HCV detection in our country is approximately $20 \%$. Untreated HCV infection advances to liver cirrhosis and/or hepatocellular carcinoma (HCC) in $15-30 \%$ of cases; it can also lead to numerous extrahepatic manifestations resulting from HCV replication in other than hepatic cells as well as from chronic inflammation [5-7].

It has been recently observed that in patients with confirmed coronary or carotid artery disease resulting 
from atherosclerosis the prevalence of $\mathrm{HCV}$ is higher than in age-matched healthy controls [8-18]. Moreover, several reports indicate that HCV infection may be associated with increased risk of death due to cardiovascular events [19], as well as with higher prevalence and mortality from cerebral infarct [20-22]. Consequently, it has been suggested that $\mathrm{CHC}$ may be one of the etiological factors contributing to development of atherosclerosis and insulin resistance [23, 24].

On the other hand, recently developed new direct acting antivirals (DAAs) provide a breakthrough for the treatment of CHC. Sustained virological response (SVR) rates achieved with DAAs exceed 95\% [25-27]. Moreover, in contrast to interferon-based therapies, novel DAAs do not exert a negative effect on the vascular endothelium and can be safely administered to patients with advanced atherosclerosis [28, 29].

For that reason, we made an attempt to test the hypothesis stating that in patients with coronary artery disease HCV infection occurs more often than in controls and that it may be one of the etiological factors for cardiovascular events.

The study objective was to investigate the exact prevalence of $\mathrm{HCV}$ infection in patients with clinically confirmed ischemic heart disease (IHD) undergoing diagnostic coronary angiography compared to a control group of patients hospitalised in the Dermatology Department.

\section{Material and methods}

\section{Study period and location}

The study was conducted in Biegański Regional Specialist Hospital in Lodz (Poland) over a period from February 2016 to December 2017 among patients hospitalised in the Cardiology Department and Dermatology Department. All subjects received comprehensive information about study methods and objectives and provided informed consent. The study received approval of the Medical University of Lodz research ethics committee. Testing for the presence of anti-HCV antibodies was performed with the support of Abbvie Poland.

\section{Patients}

The study included a group of consecutive adult patients admitted to Cardiology and Dermatology Departments who met the following criteria.

Inclusion criteria:

1. Consecutive adult patients with chest pain leading to clinical suspicion of IHD and referred for coronary arteriography.
2. Consecutive adult patients admitted to the Dermatology Department.

Exclusion criteria:

1. Lack of capacity or refusal to give informed consent.

\section{Methods}

Every patient had a supplemental $2 \mathrm{ml}$ blood sample taken to determine the presence of anti-HCV antibodies in the course of routine laboratory examinations performed during hospitalisation. One-time anti-HCV testing was performed in Biegański Regional Specialist Hospital Central Laboratory using the antiHCV II ECLIA method (Roche Diagnostics). The result of the test was conveyed orally to every subject and reported in their medical record. Cases of seropositive or indeterminate results were then transferred to the Infectious Diseases and Hepatology Department and had a HCV RNA PCR test (Cobas HCV RNA, Roche Diagnostics) performed to confirm or rule out active infection. Further diagnostic in the Infectious Diseases Department setting was voluntary and dependent on each patient's decision. The study population was divided into two groups according to the department (group K - Cardiology Department, group D - Dermatology Department). Age, gender and concomitant diseases were then evaluated in anti-HCV seropositive patients and in patients with confirmed infection based on the presence of HCV RNA.

\section{Statistical analysis}

For the comparison of categorical variables the chi-square test was used. A $p$ value $<0.05$ was selected as the significance threshold. Statistical analysis was performed using STATISTICA version 13.1 software (StatSoft).

\section{Results}

Over a 23-month period a total of 1171 patients underwent anti-HCV testing: 672 patients in the Cardiology Department (K group) and 499 patients in the Dermatology Department (D group). Six hundred and seventy-eight patients were male $(57.2 \%)$ and mean age in the whole study group was 58.5 years (range: 18-98 years). No significant differences between groups in terms of age and sex were observed: men represented $63.7 \%(428 / 672)$ of the population in group $\mathrm{K}$ and $50.1 \%(250 / 499)$ of the population in group D ( $p>0.05$ ); mean age in $\mathrm{K}$ and $\mathrm{D}$ groups was 66.2 and 48.2 years, respectively $(p>0.05)$. However, patients aged over 40 years represented $95.1 \%$ and $63.7 \%$ of the 
population in groups $\mathrm{K}$ and $\mathrm{D}$, respectively (significant difference, $p=0.0001$ ). Complete study group characteristics are summarized in Table 1.

Of 1171 patients with anti-HCV testing, 28 (2.4\%) tested positive: $15(2.23 \%)$ and $13(2.61 \%)$ in groups $\mathrm{K}$ and $D$, respectively. This difference was not statistically significant $(p>0.05)$. Patients aged over 40 years represented $82.1 \%$ of all seropositive subjects $(23 / 28)$.

In group K, 15/15 (100\%) of anti-HCV positive patients were over 40 years old. In group D, 8/13 (61.5\%) of anti-HCV positive patients were over 40 years old; that difference was statistically significant $(p=0.00805)$. The results are presented in Table 2.

All patients with positive anti-HCV antibodies underwent further HCV RNA testing. Presence of HCV RNA was confirmed in 15 cases (1.28\%) - 7 patients in group $\mathrm{K}$ and 8 patients in group D (1.04\% and $1.6 \%$, respectively; $p>0.05$ ). Of these 15 cases 13 patients were over 40 years old: $7 / 7$ patients in group $\mathrm{K}$ and $6 / 8$ patients in group D. In ten out of fifteen subjects with confirmed $\mathrm{HCV}$ infection viral genotype was determined ( 6 and 4 cases in groups $K$ and $D$, respectively). Two patients died before genotype assessment

Table 1. Study group characteristics

\begin{tabular}{lcccc}
\hline Study group & $\begin{array}{c}\text { Cardiology } \\
\text { Department }\end{array}$ & $\begin{array}{c}\text { Dermatology } \\
\text { Department }\end{array}$ & $\begin{array}{c}\text { Total, } \\
\boldsymbol{n}(\%)\end{array}$ & $p$ \\
\hline Gender & & & \\
\hline Female & $244(36.3)$ & $249(49.9)$ & $493(42.1)$ & $>0.05$ \\
\hline Male & $428(63.7)$ & $250(50.1)$ & $678(57.2)$ & $>0.05$ \\
\hline Age (years) & \multicolumn{5}{c}{} & \\
\hline Mean & 66.2 & 48.2 & \\
\hline Range & $23-95$ & $18-98$ & \\
\hline$>40$ years old & $639(95.1)$ & $318(63.7)$ & $957(81.7)$ & 0.00001 \\
\hline Total & 672 & 499 & 1171 & \\
\hline \multicolumn{5}{c}{}
\end{tabular}

was performed and three patients were lost to follow-up and did not undergo further investigation. In one $(1 / 5)$ patient in group $\mathrm{K}$, qualified for treatment, liver cirrhosis (F4) was confirmed. In other patients in group $\mathrm{K}$, advanced fibrosis (F3) (1/5 patients) and mild fibrosis (F2) (3/5 patients) were diagnosed. No patients with vascular etiology of liver cirrhosis were diagnosed. In 5 patients qualified for DAA treatment in group $\mathrm{D}$, in one case $(1 / 5)$ we confirmed advanced fibrosis (F3), and in 4 cases (4/5) mild fibrosis (F1-F2). Among group $\mathrm{D}$ patients, we did not find a relations between HCV infection and skin diseases.

In nine out of ten cases genotype $1 \mathrm{~b}$ was identified, while one patient had genotype 3a infection. All ten patients were started on antiviral treatment: in 7 cases a sustained viral response (SVR) after 12 weeks was achieved, while 3 patients are still on treatment.

\section{Discussion}

Contrary to what was expected, we did not find any statistically significant difference in the prevalence of anti-HCV antibodies between the two study groups (2.2\% and $2.6 \%$ in patients from Cardiology $[\mathrm{K}]$ and Dermatology [D] departments, respectively). Presence of serum HCV RNA was found in $1.04 \%$ of patients from group $\mathrm{K}$ and in $1.6 \%$ of patients from group $\mathrm{D}$, but again, the difference was not statistically significant.

The hypothesis stating that the risk of atherosclerosis (including coronary artery disease) can be increased by HCV seropositivity was the starting point of our analysis. It has been supported by recently published reports [12-14] proving that HCV infection stimulates chronic inflammation and may contribute to endothelial dysfunction $[5,8,23]$.

Numerous authors have reported that the risk of atherosclerosis, myocardial infarcts and cerebral in-

Table 2. Anti-HCV and HCV-RNA testing results according to the study groups

\begin{tabular}{lcccc}
\hline Study groups & Total, $n(\%)$ & $\begin{array}{c}\text { Cardiology Department, } \\
n(\%)\end{array}$ & $\begin{array}{c}\text { Dermatology Department, } \\
n(\%)\end{array}$ & $p$ \\
\hline Anti-HCV positive, $n(\%)$ & $28(2.4)$ & $15(2.23)$ & $13(2.61)$ & $>0.05$ \\
\hline Females & $12(2.43)$ & 7 & 5 & $>0.05$ \\
\hline Males & $16(2.36)$ & 8 & 8 & $>0.05$ \\
\hline Patients $>40$ years old & $23(2.4)$ & 15 & 8 & 0.00805 \\
\hline HCV-RNA positive, $n(\%)$ & $15(1.28)$ & $7(1.04)$ & $8(1.6)$ & $>0.05$ \\
\hline Females & $7(1.42)$ & 4 & 3 & $>0.05$ \\
\hline Males & $8(1.18)$ & 3 & 5 & $>0.05$ \\
\hline$>40$ years old & $13(1.36)$ & 7 & 6 & $>0.05$ \\
\hline$<40$ years old & $2(0.93)$ & 0 & 2 & $>0.05$ \\
\hline
\end{tabular}


farcts, as well as deaths from cardiovascular events, was higher in HCV-seropositive patients than in the general population [15-20]. An association between risk of cardiovascular events and presence of serum HCV RNA, as well as viral load $[6,7,13]$, has also been proven. This analysis does not support the aforementioned findings. Our study included assessment of the exact prevalence of anti-HCV antibodies and serum HCV RNA in patients with clinically confirmed ischemic heart disease undergoing diagnostic coronary angiography (blood samples were taken in the Haemodynamics Unit just prior to the procedure) compared to the control group of patients hospitalised in the Dermatology Department due to skin diseases.

There were no statistically significant differences in terms of age and gender between the groups. However, a slightly higher men-to-women ratio, as well as higher mean age (and higher percentage of patients over 40 years old) in group $\mathrm{K}$ could, according to the baseline hypothesis, contribute to the increased prevalence of results positive for anti-HCV antibodies and serum HCV RNA.

The study protocol did not allow us to exclude the possibility that patients from group $\mathrm{D}$ were suffering from coronary artery disease. We also did not perform an analysis of $\mathrm{HCV}$ infection markers according to the results of coronary angiography. These limitations, however, are typical for broad screening programmes.

Above-cited authors, however, compared seronegative and seropositive patients with one illness instead of comparing groups with various concomitant diseases. The results of the present analysis suggest that prevalence of $\mathrm{HCV}$ infection in patients with comorbidities is higher than in the general population: the virus itself can be a predisposing factor for the development of a disease or a result of medical procedures associated with pre-existing conditions.

An important observation coming from our research is the higher prevalence of positive anti-HCV antibodies and serum HCV RNA than in other Polish general population screening studies. Rates of antiHCV positive and HCV RNA positive patients in our population were $2.4 \%$ and $1.3 \%$, respectively. In a recently conducted study including patients consulting general practitioners prevalence of positive anti-HCV antibodies was $0.46 \%$ (data accepted for print).

Main risk factors for the presence of anti-HCV antibodies included blood transfusions before 1992 and history of at least 3 hospitalisations.

Results of a study conducted in our country in the years 2012-2016 as part of the "Swiss Programme" indicate that prevalence of positive serum HCV RNA in the general population is $0.47 \%$ [4].
The results of the present study not only seem to expand the knowledge about the association between hepatitis $\mathrm{C}$ and ischemic heart disease, but also allowed the detection and successful treatment of $\mathrm{HCV}$ infection in 10 new patients.

\section{Conclusions}

Our study did not prove an association between HCV infection and presence of symptomatic IHD. However, we observed that the prevalence of $\mathrm{CHC}$ in patients hospitalised in the Cardiology and Dermatology Departments was nearly five times higher than in the general population. Our findings suggest that this patient cohort has increased risk of $\mathrm{HCV}$ infection, which may influence screening strategies.

\section{Acknowledgments}

We thank Abbvie Polska Sp. z o.o. for transferring funds for performing anti-HCV tests in patients participating in this study.

\section{Disclosure}

Authors report no conflict of interest.

\section{References}

1. Colpitts CC, Verrier ER, Baumert TF. Targeting viral entry for treatment of hepatitis B and C virus infections. ACS Infect Dis 2015; 1: 420-427.

2. Wiktor S. Where next for hepatitis B and C surveillance? J Viral Hepat 2015; 22: 571-573.

3. Hatzakis A, Chulanov V, Gadano AC, et al. The present and future disease burden of hepatitis $\mathrm{C}$ virus (HCV) infections with today's treatment paradigm - volume 2. J Viral Hepat 2015; 22 (Suppl 1): 26-45.

4. Rosińska M, Parda N, Kołakowska A, et al. Factors associated with hepatitis $\mathrm{C}$ prevalence differ by the stage of liver fibrosis: A cross-sectional study in the general population in Poland, 20122016. PLoS One 2017; 12: e0185055.

5. Forton D, Craxì A, Sulkowski MS, et al. Extrahepatic morbidity and mortality of chronic hepatitis C. Gastroenterology 2015; 149: 1345-1360.

6. Tsui JI, Whooley MA, Monto A, et al. Association of hepatitis C virus seropositivity with inflammatory markers and heart failure in persons with coronary heart disease: data from the Heart and Soul study. J Card Fail 2009; 15: 451-456.

7. Lee MH, Yang HI, Lu SN, et al. Chronic hepatitis $\mathrm{C}$ virus infection increases mortality from hepatic and extrahepatic diseases: a community-based long-term prospective study. J Infect Dis 2012; 206: 469-477.

8. Maruyama $\mathrm{S}^{1}$, Koda $\mathrm{M}$, Oyake N, et al. Myocardial injury in patients with chronic hepatitis C infection. J Hepatol 2013; 58: 11-15.

9. Lin MS, Guo SE, Chen MY, et al. The impact of hepatitis C infection on ischemic heart disease via ischemic electrocardiogram. Am J Med Sci 2014; 347: 478-484. 
10. Butt AA, Xiaoqiang W, Budoff M, et al. Hepatitis C virus infection and the risk of coronary disease. Clin Infect Dis 2009; 49: 225-232.

11. Freiberg MS, Chang CC, Skanderson M, et al. The risk of incident coronary heart disease among veterans with and without HIV and hepatitis C. Circ Cardiovasc Qual Outcomes 2011; 4: 425-432.

12. Vassalle C, Masini S, Bianchi F, et al. Evidence for association between hepatitis $\mathrm{C}$ virus seropositivity and coronary artery disease. Heart 2004; 90: 565-566.

13. Pothineni NV, Delongchamp R, Vallurupalli S, et al. Impact of hepatitis $\mathrm{C}$ seropositivity on the risk of coronary heart disease events. Am J Cardiol 2014; 114: 1841-1845.

14. Hsu YH, Muo CH, Liu CY, et al. Hepatitis C virus infection increases the risk of developing peripheral arterial disease: a 9-year population-based cohort study. J Hepatol 2015; 62: 519-525.

15. Ishizaka Y, Ishizaka N, Takahashi E, et al. Association between hepatitis $C$ virus core protein and carotid atherosclerosis. Circ J 2003; 67: 26-30.

16. Ishizaka N, Ishizaka $\mathrm{Y}$, Takahashi E, et al. Association between hepatitis $\mathrm{C}$ virus seropositivity, carotid-artery plaque, and intima-media thickening. Lancet 2002; 359: 133-135.

17. Petta S, Torres D, Fazio G, et al. Carotid atherosclerosis and chronic hepatitis C: a prospective study of risk associations. Hepatology 2012; 55: 1317-1323.

18. Kiechl S, Egger G, Mayr M, et al. Chronic infections and the risk of carotid atherosclerosis: prospective results from a large population study. Circulation 2001; 103: 1064-1070.

19. Petta S, Maida M, Macaluso FS, et al. Hepatitis C Virus infection is associated with increased cardiovascular mortality: a meta-analysis of observational studies. Gastroenterology 2016; 150: 145-155.

20. Liao CC, Su TC, Sung FC, et al. Does hepatitis C virus infection increase risk for stroke? A population-based cohort study. PLoS One 2012; 7: e31527.

21. Adinolfi LE, Restivo L, Guerrera B, et al. Chronic HCV infection is a risk factor of ischemic stroke. Atherosclerosis 2013; 231: 22-26.

22. Lee MH, Yang HI, Wang CH, et al. Hepatitis C virus infection and increased risk of cerebrovascular disease. Stroke 2010; 41: 2894-2900.

23. Negro F. Facts and fictions of HCV and comorbidities: steatosis, diabetes mellitus, and cardiovascular diseases. J Hepatol 2014; 61 (1 Suppl): S69-78.

24. Tomiyama H, Arai T, Hirose K, et al. Hepatitis C virus seropositivity, but not hepatitis B virus carrier or seropositivity, associated with increased pulse wave velocity. Atherosclerosis 2003; 166: 401-403.

25. Lawitz E, Makara M, Akarca US, et al. Efficacy and safety of ombitasvir, paritaprevir, and ritonavir in an open-label study of patients with genotype $1 \mathrm{~b}$ chronic hepatitis $\mathrm{C}$ virus infection with and without cirrhosis. Gastroenterology 2015; 149: 971-980.

26. Flisiak R, Janczewska E, Wawrzynowicz-Syczewska M, et al. Real-world effectiveness and safety of ombitasvir/paritaprevir / ritonavir \pm dasabuvir \pm ribavirin in hepatitis C: AMBER study. Aliment Pharmacol Ther 2016; 44: 946-956.

27. Flisiak R, Łucejko M, Mazur W, et al. Effectiveness and safety of ledipasvir/sofosbuvir \pm ribavirin in the treatment of $\mathrm{HCV}$ infection: The real-world HARVEST study. Adv Med Sci 2017; 62: 387-392.

28. Smith-Palmer J, Cerri K, Valentine W. Achieving sustained virologic response in hepatitis C: a systematic review of the clinical, economic and quality of life benefits. BMC Infect Dis 2015; 15: 19.
29. Desmond CP, Roberts SK, Dudley F, et al. Sustained virological response rates and durability of the response to interferon-based therapies in hepatitis $\mathrm{C}$ patients treated in the clinical setting. J Viral Hepat 2006; 13: 311-315. 